\section{Trifurcated hepatic duct with low union complicated by choledocholithiasis}
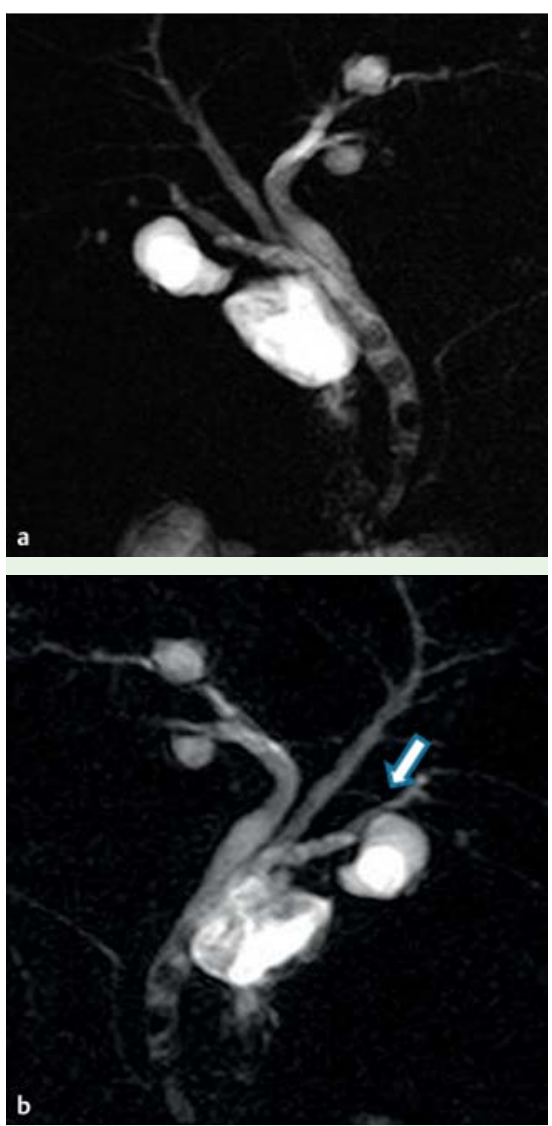

Fig. 1 Magnetic resonance cholangiopancreatography (MRCP) findings. a Anterior coronal image demonstrating trifurcation of the bile ducts. The confluence of the anterior and posterior branches of the right hepatic duct has joined the left hepatic duct. b Posterior coronal image demonstrating the outlet of the cystic duct into the right posterior segmental duct (arrow).

A 74-year-old man was admitted to our hospital with right upper quadrant pain. Laboratory data on admission were as follows: aspartate transaminase (AST) 26IU/ L, alanine transaminase (ALT) $70 \mathrm{IU} / \mathrm{L}$, total bilirubin $0.9 \mathrm{mg} / \mathrm{dL}$, alkaline phosphatase $337 \mathrm{U} / \mathrm{L}$, and $\gamma$-glutamyl transpeptidase 552 U/L. Magnetic resonance cholangiopancreatography (MRCP) revealed a trifurcated configuration of hepatic ducts with an unusual low union, and drainage of the cystic duct into the right posterior segmental duct, accompanied by several common bile duct (CBD) stones ( $\bullet$ Fig. 1 ). Endoscopic retrograde cholangiopancreatography (ERCP) revealed similar findings to those of the MRCP. The CBD stones were
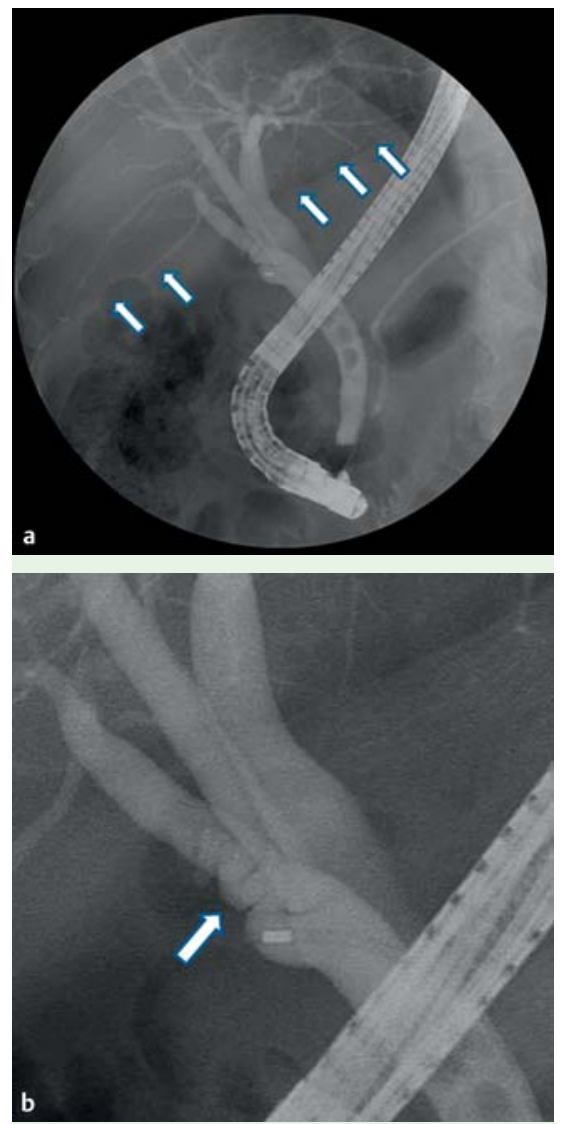

Fig. 2 Endoscopic retrograde cholangiopancreatography (ERCP) findings. a Cholangiogram demonstrating low union of the right and left hepatic duct with calculus in the common bile duct. The arrows indicate the inferior margin of the liver. No gallbladder was seen because of chronic cholecystitis. b Magnified view demonstrating drainage of the cystic duct into the right posterior segmental duct (arrow).

removed successfully using a retrieval basket after endoscopic sphincterotomy ( Fig. 2). After 4 days, the patient underwent cholecystectomy followed by hepaticojejunostomy.

To the best of our knowledge, this unusual anomaly has not been described previously. This case is of clinical significance because such an anomaly could lead to accidental dissection or ligation of the bile duct during laparoscopic cholecystectomy. Triple confluence of the right anterior and posterior segmental ducts and the left hepatic duct is known to occur in up to $10 \%$ of hepatic duct variations [1]. Drainage of the cystic duct directly into the right hepatic duct at a low level is quite rare [2]. The pat- tern of variation in some hepatic ducts may eventually lead to impaired bile flow and bile stasis, subsequently resulting in bacterial overgrowth and formation of primary bile duct stones. Any ligation or dissection of the hepatic duct will result in potentially fatal complications, such as bile leakage, partial biliary obstruction, ductal stricture, cholangitis, or biliary cirrhosis [3-5]. In order to avoid serious iatrogenic injuries of the bile duct, thorough interpretation and accurate diagnosis of any anatomical variation of the biliary tree is emphasized.

Endoscopy_UCTN_Code_CCL_1AZ_2AK

Competing interests: None

\section{J. H. Yang, K. H. Kim, T. N. Kim}

Department of Internal Medicine, Yeungnam University College of Medicine, Daegu, Korea

\section{References}

1 Schofield A, Hankins J, Sutherland F. A case of cholecystohepatic duct with atrophic common hepatic duct. HPB 2003; 5: 261-263

2 De Filippo $M$, Calabrese M, Quinto $S$ et al. Congenital anomalies and variations of the bile and pancreatic ducts: magnetic resonance cholangiopancreatography findings, epidemiology and clinical significance. La Radiologia Medica 2008; 113: 841 - 859

3 Brandt CP, Eckhauser ML. Rare bile duct anomalies. A case report and implications for laparoscopic cholecystectomy. Surg Endosc 1994; 8: 329-331

4 Hafner M, Schofl R, Gangl A. A rare anomaly of the biliary tree: the interhepatic duct. Gastrointest Endosc 1997; 45: 523-525

5 Moo-Young TA, Picus DD, Teefey S et al. Common bile duct injury following laparoscopic cholecystectomy in the setting of sinistroposition of the gallbladder and biliary confluence: a case report. J Gastrointest Surg 2010; 14: $166-170$

\section{Bibliography}

Dol http://dx.doi.org/

10.1055/s-0032-1326107

Endoscopy 2013; 45: E74

(c) Georg Thieme Verlag KG

Stuttgart · New York

ISSN 0013-726X

\section{Corresponding author \\ T. N. Kim}

Division of Gastroenterology and Hepatology

Department of Internal Medicine

Yeungnam University College of Medicine

317-1 Daemyung-dong

Nam-gu, Daegu

Korea

Fax: +82-53-6548386

tnkim@yu.ac.kr 